\title{
ENVOLVIMENTO DE MULHERES COM ENTORPECENTES: FREQUENNCIAS TEMPORAIS E IMPLICAÇÕES SOCIAIS
}

\author{
INVOLVEMENT OF WOMEN WITH NARCOTICS: \\ TEMPORAL FREQUENCY AND SOCIAL \\ IMPLICATIONS
}

\author{
Maria das Graças Rocha de Souza Affonso* \\ Walterley Barcelos ${ }^{* *}$ \\ Douglas Bittencourt ${ }^{* * *}$ \\ Heury Ferreira $^{* * *}$ \\ Alvorita Leite Bittencourt ${ }^{* * * *}$
}

\begin{abstract}
RESUMO
Avaliou-se o envolvimento de mulheres com o tráfico e/ou o uso de cocaína e maconha em apreensões ocorridas entre 2005 e 2010 em Santa Catarina, Brasil. Utilizaram-se os dados totais do estado, cadastrados no Instituto de Análises Forenses, correspondentes às apreensões de cocaína, maconha e cocaína+maconha em posse só de mulheres ou simultaneamente com homens. Nas regiões da Grande Florianópolis e do Vale do Itajaí os resultados mostraramse interessantes. Em 2005, na Grande Florianópolis, havia o predomínio de apreensões de maconha, que reverteu-se para cocaína em 2008 e retornou para maconha em 2010. Na região do Vale do Itajaí, houve uma evolução constante das apreensões de cocaína, com aumento escalonado de 307\% em 2010. As apreensões de maconha e cocaína+maconha, foram maiores no Vale do Itajaí, região Sul e Grande Florianópolis. Observou-se o predomínio da participação de mulheres com o tráfico e/ou o uso de cocaína em cinco das seis regiões de Santa Catarina, demonstrando a necessidade de políticas sociais fortes para frear esse crescimento. $\mathrm{O}$ trabalho discute a problemática social do uso/tráfico de entorpecentes por mulheres.
\end{abstract}

Palavras-chave: Mulheres. Apreensões. Cocaína. Maconha. Entorpecentes

\footnotetext{
*Farmácia e Bioquímica pela UFSC, Florianópolis/SC.Especialização em Segurança Pública e Cidadania pela Assessoria Universitária Pedagógica de Extensão, Florianópolis, SC. Perita Criminal Bioquímica do IGP, Instituto de Análises Forenses, Florianópolis/SC. maffonso1@gmail.com

** Formação em Bacharel em Administração de Empresas, Universidade do Vale do Itajaí (UNIVALI), Itajaí/SC.Papiloscopista do IGP, Instituto de Análises Forenses, Florianópolis/SC.wjb@igp.sc.gov.br

${ }^{* * *}$ Medicina pela Univ ersidade da Região de Joinville (UNIVILLE). Médico da Unidade de Pronto Atendimento de Biguaçu (UPA)/SC douglas.medicina@ hotmail.com

**** Ciências Biológicas.Mestrado e Doutorado em Ecologia Teórica e Evolução Empresário da Yalo Consultoria Científica e Estatística. heury.yalo@gmail.com

${ }^{* * * *}$ Farmácia e Análises Clínicas pela UFSC, Florianópolis/SC. Doutorado em Toxicologia e Análises Toxicológicas pela Universidade de São Paulo, São Paulo/SP. Perita Criminal Bioquímica do IGP, Instituto de Análises Forenses, Florianópolis/SC.alvorita@terra.com.br
} 


\begin{abstract}
We evaluated the involvement of women in trafficking and/or use of cocaine and marijuana in apprehension occurred between 2005 and 2010 in the State of SC, Brazil. We used the total data of the State, registered at the Institute for Forensic Analysis, corresponding to the apprehension of cocaine; marijuana; cocaine+marijuana in possession only of women or simultaneously with men. In regions of Florianópolis and the Vale do Itajai results were interesting. In 2005 in Florianópolis, there was a predominance of apprehension of marijuana, which was reversed for cocaine in 2008 and returned in 2010 for marijuana. In the region of Vale do Itajaí, there was a constant evolution of apprehension of cocaine, with stepwise increase of $307 \%$ in 2010. Apprehension of marijuana and cocaine+marijuana were higher in the Itajai Valley, Southern and Florianópolis. Predominated of women's participation in trafficking and/or use of cocaine in five of the six regions of SC, demonstrating the need for social policies to break this growth. The paper discusses the problem of the social use / trafficking of narcotics by women.
\end{abstract}

Keywords: Women. Apprehension. Cocaine. Marijuana. Narcotics

\section{Introdução}

A maconha é a droga ilícita mais consumida em todo o mundo. Segundo o II Levantamento Domiciliar sobre Uso de Drogas Psicotrópicas no Brasil (2005), houve um aumento expressivo entre as proporções de indivíduos que relataram ter consumido maconha pelo uma vez nos últimos trinta dias da pesquisa, entre 2001 e 2005, correspondente a $0,6 \%$ e $1,9 \%$, respectivamente, de um total de 7.939 entrevistados.

O Delta 9 tetraidrocanabinol $(\Delta 9$-THC), principal constituinte ativo da maconha, e a cocaína são substâncias psicotrópicas naturalmente produzidas pelas espécies vegetais Cannabis sativa e Erytroxylon coca, respectivamente.

A maconha é o produto formado pela mistura de folhas secas, caules, sementes e sumidades floridas da Cannabis sativa, apresentando de $2 \%$ a $5 \%$ de $\triangle 9$-THC em condições naturais de cultivo. Após a secagem, o material é bem triturado e está pronto para ser fumado na forma de cigarro artesanal ou cachimbo, mas também pode ser utilizado no preparo de chás e algumas vezes na mistura com alimentos. $\mathrm{O} \Delta 9$-THC está presente em grande quantidade nas inflorescências, níveis menores nas folhas, mas está ausente na semente. A extração da resina da planta vai dar origem ao haxixe, com aproximadamente $15 \%$ de $\Delta 9$-THC; o óleo de haxixe é obtido por destilação do haxixe, apresentando em torno de $30 \%$ de A9-THC (Unodc, 2010; Queiroz, 2008).

Por outro lado, a cocaína pura é extraída das folhas da Erytroxylon coca por processo artesanal, sendo administrada por via oral, intranasal e intravenosa, na forma de cloridrato (pó), e por inalação, na forma de base livre como pasta, crack e merla (NIDA, 2010). A quantidade de cocaína no produto final depende do processo artesanal de fabricação. A mastigação das folhas de coca é utilizada há muitos anos pelos povos nativos da América do Sul, visando suportar a fome, a sede e o cansaço. Atualmente é consumida de forma legal em alguns países como Peru e Bolívia, sob a forma de chá, cuja absorção do princípio ativo é muito baixa (Queiroz, 2008).

Tem-se observado que as apreensões de maconha parecem estar crescendo mais fortemente na América do Sul, em especial no Estado Plurinacional da Bolívia, que apresentou um aumento adicional de $74 \%$ em 2009 em relação ao ano anterior, embora a prevalência anual do uso de maconha continue consideravelmente inferior ao da América do Norte. Nesse mesmo sentido, as 
apreensões de cocaína na América do Sul atingiram níveis recordes em 2008, totalizando 418 toneladas (base e cloridrato), um pouco a mais do que o total de 2007 (322 toneladas), apresentando um aumento de $62 \%$ no Estado Plurinacional da Bolívia, 51\% na Argentina, $21 \%$ no Brasil e $12 \%$ no Equador (Unodc, 2010).

As maiores prevalências do uso de maconha na América do Sul, entre a população de 15-64 anos em 2007, foram encontradas na Argentina (7,2\%), Chile (6,7\%), Uruguai $(6,0 \%)$, Bolívia (4,3\%), Brasil (2,6\%), Colômbia (2,3\%) e Paraguai (1,6\%). Com relação à cocaína, as maiores prevalências nessa mesma faixa etária, em 2008, foram encontradas na Argentina (2,7\%), Chile $(2,4 \%)$ e Uruguai $(1,4 \%)$. Brasil e Argentina constituem os maiores mercados de cocaína na América do Sul em termos absolutos (mais de 900 mil e 600 mil usuários, respectivamente) (Unodc, 2010).

Os dados da América Latina e de outras partes do mundo sugerem que, quanto mais avançado o país, maior a proporção de mulheres entre usuários de drogas. Apesar de numericamente menos envolvidas com drogas, as mulheres formam um grupo vulnerável crescente, cujo consumo e envolvimento com o tráfico vem aumentando. Os problemas relacionados com o tráfico e/ou o uso entre mulheres têm uma abrangência maior e mais preocupante que os dos homens, devido à maternidade e aos cuidados futuros com as crianças (Cazenave, 1999; Chodorow, 1978).

Questões relacionadas aos entorpecentes têm sido objeto de debates na mídia brasileira. Entretanto, constatou-se a ausência de publicações com dados focados no estado de Santa Catarina (SC), envolvendo mulheres. Assim, este estudo tem como objetivo mostrar um panorama da situação real do envolvimento de mulheres com cocaína e/ou maconha em SC, mostrando dados absolutos que indicam de forma irrefutável a verdadeira situação da mulher com o tráfico e/ou o uso dessas drogas.

\section{Método}

\section{Coleta de dados e análises estatísticas}

Para este estudo, consideramos como parâmetro o número de apreensões registradas nos arquivos do Instituto de Análises Forenses (IAF). Os valores obtidos referem-se às apreensões correspondentes ao porte de cocaína, maconha, e cocaína simultaneamente com maconha, envolvendo mulheres no estado de SC no período de 2005 a 2010. Os critérios de inclusão dos dados foram participação de mulheres numa situação isolada, bem como em associação com homens, com o porte ou com o envolvimento nas apreensões de maconha e/ou cocaína.

Os dados foram avaliados por meio de técnicas de análise descritiva, que visa apresentar dados como a média de apreensões, os valores de apreensão mínimo e máximo no período de estudo, entre outras. Essa análise, embora não teste as hipóteses propriamente ditas, permite a visualização das distribuições discretas das variáveis.

Para os cálculos das porcentagens utilizamos valores modulares, a fim de evitar que fossem apresentados valores negativos, devido ao modelo baseado em subtração " $\mathrm{X}=\mid(\mathrm{V}$ ' - V)/V $\mid$ x 100".

Com o intuito de avaliar os padrões observados ao longo dos anos do estudo (2005 a 2010), as médias de apreensões foram submetidas à técnica estatística Exponential Smoothing, que fornece uma análise por séries temporais. Trata-se de uma técnica que avalia tendências existentes ao longo do tempo em uma série que avalia um cálculo ajustado, um cálculo a partir dos dados observados/coletados e um cálculo dos resíduos, que são os valores de variáveis não mensuradas que podem interferir no poder de inferência. Desta forma, é possível descrever três retas: uma referente aos valores esperados pelo modelo; uma reta referente aos valores observados; e uma reta referente aos valores de resíduo, que são referentes a variáveis não mensuradas no estudo, seja por sua natureza (dificuldade de dimensionar, i.e. motivos pessoais que interferem em suas decisões, entre outros), seja pelo fato de fugirem ao escopo do estudo. A comparação é realizada por meio das médias ao longo do tempo entre as três retas: quanto mais próxima a reta dos dados observados está da reta referente ao modelo, mais ajustados estão os dados à previsão estatística.

Quando os valores observados para os resíduos são altos, sugere-se que existem valores alheios aos mensurados que afetam a adequabilidade dos dados aos esperados pelo modelo. Entretanto, convém ressaltar que isso não afeta o modelo em si, apenas 
sugere que variáveis não consideradas podem estar afetando os dados observados. Essas variáveis não mensuradas são coletivamente agrupadas sob o epíteto de "acaso". Esse termo, portanto, referese à parcela de explicação retida nos cálculos de resíduo, ou seja, a parcela de explicação que se refere às variáveis não analisadas neste estudo (Yalo Consultoria Científica e Estatística).

\section{Resultados}

Apreensões de cocaína e/ou maconha por região, envolvendo mulheres

A exposição dos resultados da somatória de todos os anos avaliados, entre 2005 e 2010, separadamente por regiões de SC, proporcionou uma visualização gráfica de forma esclarecedora sobre o comportamento das apreensões de cocaína e maconha em cada região do estado, conforme mostra a figura 1.

Figura 1 - Número total de apreensões de cocaína (COC), maconha (MAC), e cocaína simultaneamente com maconha (COC-MAC), por regiões de SC, correspondente à soma dos seis anos pesquisados (2005 a 2010), envolvendo mulheres.

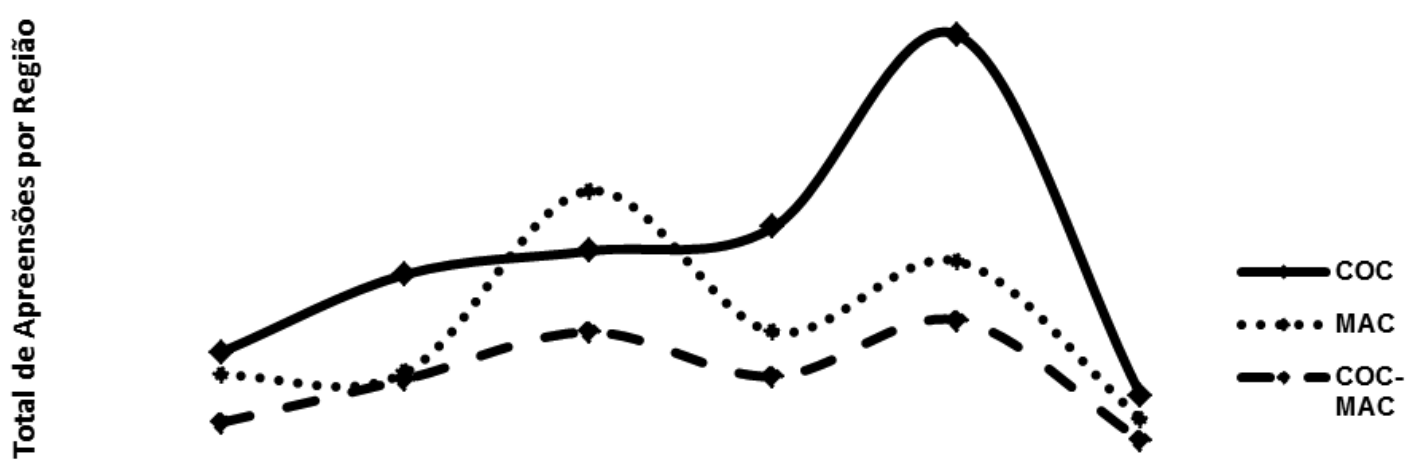

Regiões de Santa Catarina

Entre 2005 e 2010 houve um predomínio de apreensões de cocaína em cinco das seis regiões do estado. A região do Vale do Itajaí foi o local onde ocorreu o maior número de casos de cocaína, correspondendo a 632 apreensões, e essa região serviu de base para a comparação com as demais: a região Oeste correspondeu a $24,3 \%$ do total do Vale do Itajaí, a região Norte a $42,8 \%$, a Grande Florianópolis a $48,4 \%$, a região $\mathrm{Sul}$ a $54,1 \%$ e a região do Planalto Serrano correspondeu a $13,9 \%$.

Na região da Grande Florianópolis predominou o tráfico e/ou o uso de maconha, envolvendo mulheres, com um pico de 397 casos, seguida pela região do Vale do Itajaí, com 291 casos, e a região Sul, com 184 apreensões. As regiões Oeste, Norte e Planalto Serrano apresentaram 119, 123 e 53 apreensões de mulheres com o porte de maconha, respectivamente.
As apreensões de cocaína simultaneamente com maconha mostraram resultados semelhantes na Grande Florianópolis e no Vale do Itajaí, correspondendo a 184 e 202 casos, respectivamente, seguidas pela região Sul com 117 casos e região Norte com 113 apreensões. As regiões Oeste e Planalto Serrano mostraram menores números de apreensões em relação às demais regiões: 48 e 21 casos, respectivamente.

$\mathrm{Na}$ somatória total de apreensões de ambas as drogas, em ordem crescente, constataram-se 162 casos no Planalto Serrano, 321 casos na região Oeste, 507 casos na região Norte, 643 casos na região Sul, 887 casos na Grande Florianópolis e 1.125 casos no Vale do Itajaí, mostrando o perfil de cada região com o tráfico e/ou o uso de cocaína e maconha. 
Apreensões de cocaína e/ou maconha por ano, envolvendo mulheres

Investigou-se o total de apreensões de cocaína e/ou maconha como a somatória de todas as seis regiões de SC, separadamente por ano pesquisado, visando obter o perfil geral da evolução das apreensões dessas substâncias psicotrópicas, envolvendo mulheres, conforme mostra a figura 2 .
Os resultados correspondentes à cocaína mostraram uma evolução constante e acentuada no número de casos, envolvendo mulheres, entre 2005 e 2010, apresentando 165 casos em 2005 e 407 casos em 2010. Comparando-se os resultados entre esses dois anos, observou-se uma evolução de 146,6\% nas apreensões de cocaína em todo o estado de Santa Catarina.

Figura 2 - Número total de apreensões de cocaína (COC), maconha (MAC), e cocaína simultaneamente com maconha (COC-MAC), em cada ano avaliado (entre 2005 e 2010), correspondente à soma de todas as regiões de SC, envolvendo mulheres.

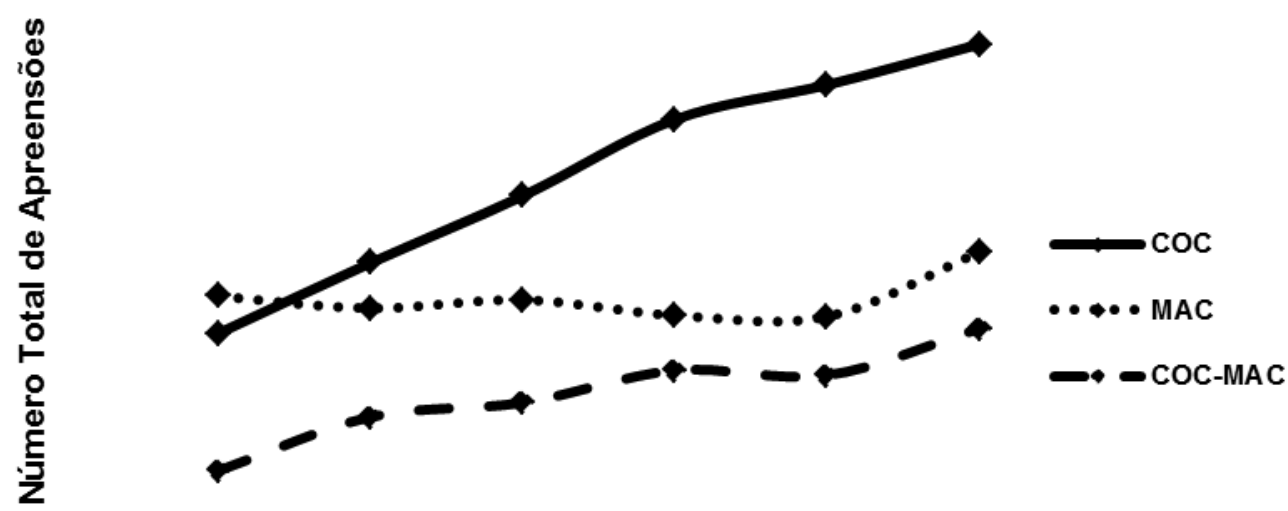

Anos Avaliados

Com relação às apreensões de maconha, foram observados resultados crescentes até 2008, estabilização em 2009 e um aumento expressivo do número de apreensões em 2010, representando $30,1 \%$ de crescimento, em comparação com o ano anterior. Entre 2005 e 2010 ocorreu evolução do envolvimento de mulheres com o tráfico e/ou o uso de cocaína simultaneamente com maconha, passando de 50 para 169 apreensões, correspondendo ao aumento de $238 \%$.

$\mathrm{Na}$ avaliação geral do envolvimento de mulheres com cocaína e maconha no estado, considerando a somatória dessas duas substâncias psicotrópicas, foi observada a ocorrência total de 411 casos em 2005, 505 em 2006, 580 em 2007, 658 em 2008, 682 em 2009 e atingindo 809 apreensões em 2010.

\section{Apreensões de cocaína, maconha, e cocaína+maconha no estado de Santa Catarina, envolvendo mulheres}

Para demonstrar o perfil dos três parâmetros analisados em todo o estado de SC foi realizada a somatória de todos os casos de apreensão desses entorpecentes que ocorreram no período de 2005 a 2010, conforme mostra a figura 3 .

Foram constatados 3.645 casos de apreensão de cocaína e/ou maconha no estado, envolvendo mulheres. Os casos de cocaína corresponderam a 49,1\% (1.793 casos) do total de apreensões; os de maconha, a 32,0\% (1.167 casos); os de apreensões simultâneas de cocaína com maconha, a 18,8\% (685 casos) do total apreendido. 
Figura 3 - Número total de apreensões de cocaína (COC), maconha (MAC), e cocaína simultaneamente com maconha (COC-MAC), em todo o estado de SC, incluindo o período entre 2005 e 2010, envolvendo mulheres

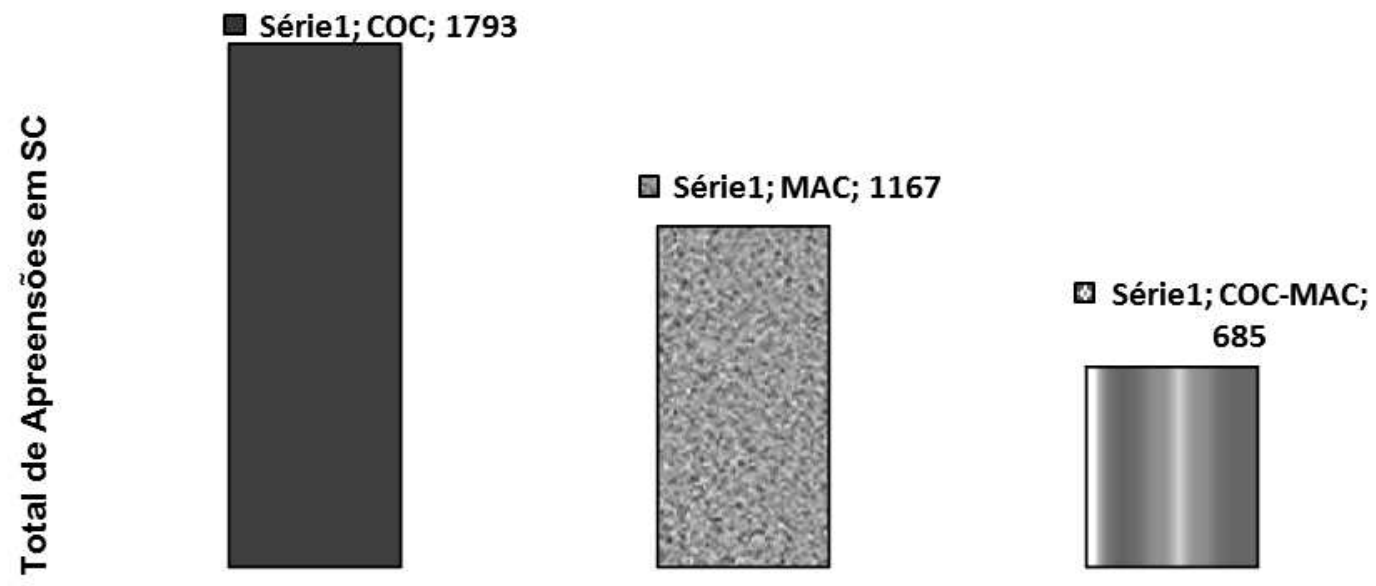

Substâncias Psicotrópicas Apreendidas

Numa avaliação mais detalhada, observou-se que as apreensões de cocaína representaram $34,9, \%$ a mais que as apreensões de maconha e $61,7 \%$ a mais que as apreensões de cocaína simultaneamente com maconha, demonstrando um predomínio significativo desse tipo de substância psicotrópica apreendida com mulheres em todo o estado.

\section{Previsão da tendência temporal das apreensões de cocaína e/ou maconha, envolvendo mulheres}

A partir dos resultados das apreensões de cocaína e/ou maconha em SC no período entre 2005 e 2010, projetou-se uma linha de tendência temporal do porte desses entorpecentes com mulheres para o ano de 2012, com o propósito de estabelecer uma estimativa estatística das previsões futuras, separadamente, para as apreensões de cocaína, maconha, e cocaína simultaneamente com maconha, nas seis regiões do estado.

\section{Região Oeste}

Na figura 4 observa-se que há uma tendência teórica prevista para um aumento ao longo dos anos (linha tracejada) das apreensões de cocaína. Os dados reais observados (linha contínua) demonstram um crescimento constante do número de apreensões de cocaína entre os anos 2005 e 2009, apresentando uma evolução de $457 \%$. A partir de 2009 houve tendência tênue de diminuição. Os resíduos (linha pontilhada) expressam a existência de muitas outras variáveis não mensuradas no delineamento, que afetam o ajuste da série observada em relação à série tratada.

Figura 4 - Previsão da tendência temporal das apreensões de mulheres com o porte de cocaína para o ano de 2012 na região Oeste (C-Oeste). Utilizou-se o teste estatístico Exponential Smoothing para a análise de tendência em séries temporais.

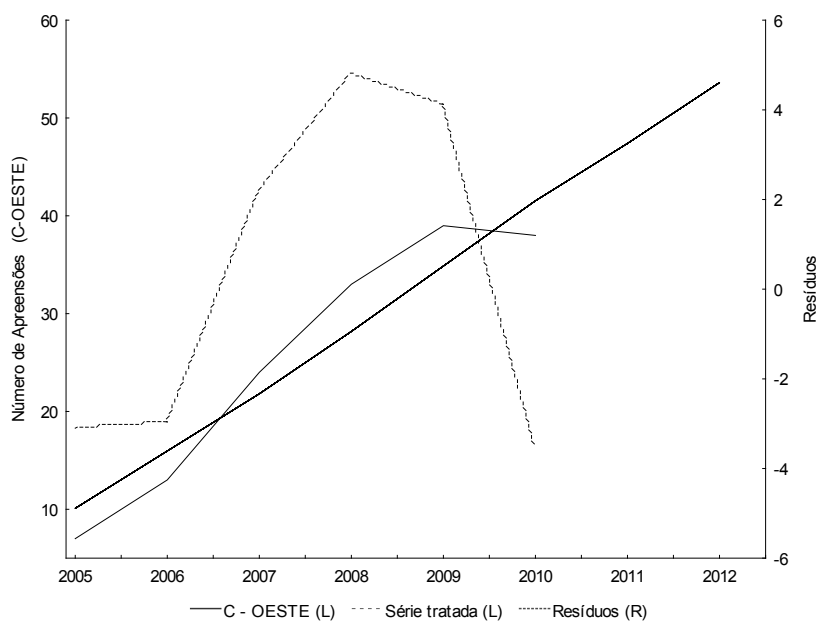


Na figura 5 observa-se que há uma tendência teórica prevista para uma diminuição ao longo dos anos (linha tracejada) das apreensões de maconha para a região Oeste, sugerindo que fatores atribuídos ao acaso (ou seja, aquelas variáveis fora do escopo deste estudo) podem ser responsáveis por tal fato. Os dados reais observados (linha contínua) demonstram que houve um decréscimo do número de apreensões até 2008. Entretanto, esse perfil foi alterado com a tendência a um grande aumento em 2009 e 2010, representado por um acréscimo importante de $78,6 \%$, atingindo um número de apreensões um pouco abaixo do patamar inicial em 2005. O ajuste dos resíduos (linha pontilhada) à reta relativa aos dados reais demonstra que variáveis alheias ao modelo detêm grande parte da explicação.

Figura 5 - Previsão da tendência das apreensões de mulheres com o porte de maconha para o ano de 2012 para a região Oeste (M-Oeste). Utilizou-se o teste estatístico Exponential Smoothing para a análise de tendência em séries temporais.

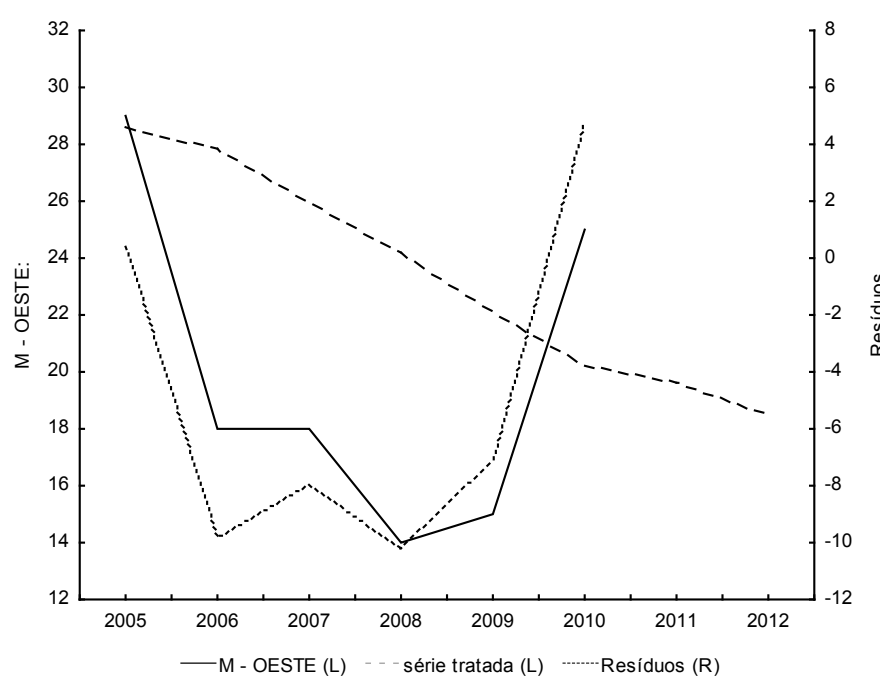

Na figura 6 observa-se que há uma tendência teórica prevista para um aumento ao longo dos anos (linha tracejada) das apreensões de cocaína simultaneamente com maconha para a região Oeste. Os dados reais observados (linha contínua) mostram um pico em 2007 e uma tendência a um aumento amortizado a partir do ano de 2009.

Os resíduos (linha pontilhada) expressam a existência de muitas outras variáveis, não mensuradas no delineamento, que afetam o ajuste da série observada em relação à série tratada.
Figura 6 - Previsão da tendência das apreensões de mulheres com o porte de cocaína simultaneamente com maconha para o ano de 2012 para a região Oeste (CM-Oeste). Utilizou-se o teste estatístico Exponential Smoothing para a análise de tendência em séries temporais.

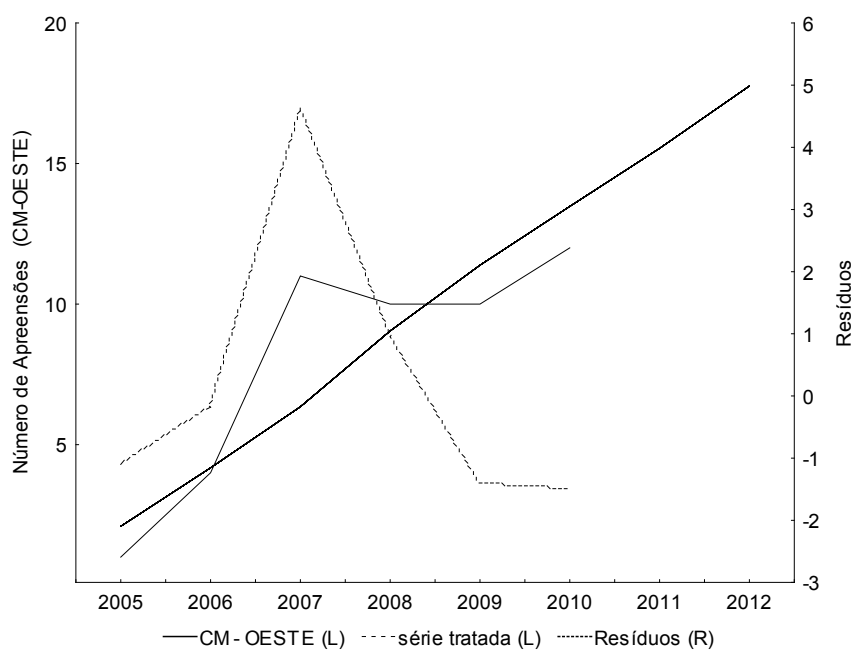

\section{Região Norte}

Na figura 7 observa-se que há uma tendência teórica prevista para um aumento ao longo dos anos (linha tracejada) das apreensões de cocaína. Os dados reais observados (linha contínua) demonstram que há uma tendência a um aumento próximo ao previsto pelo modelo de tendência em séries temporais, a partir do ano de 2008. A evolução do número de apreensões de cocaína entre 2005 e 2010 representou um crescimento de $97 \%$. Entretanto há um aumento nos resíduos (linha pontilhada), o que sugere que outros fatores interferem no aumento da tendência de apreensão de mulheres com porte dessa substância psicotrópica ilegal. 
Figura 7 - Previsão da tendência das apreensões de mulheres com o porte de cocaína para o ano de 2012 para a região Norte (C-Norte). Utilizou-se o teste estatístico Exponential Smoothing para a análise de tendência em séries temporais.

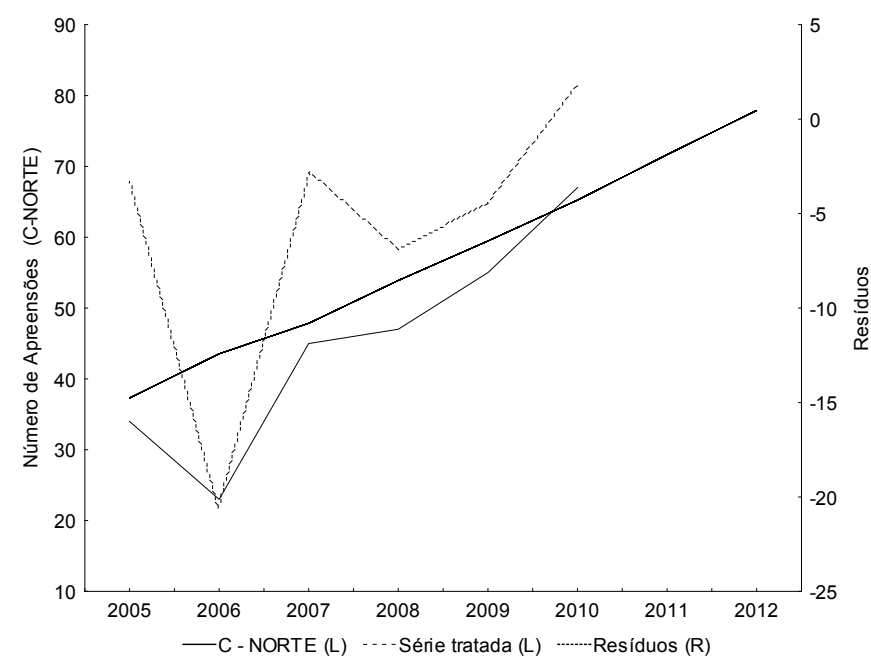

Na figura 8 observa-se que há uma tendência teórica prevista para um aumento ao longo dos anos (linha tracejada) das apreensões de maconha. Os dados reais observados (linha contínua) demonstram que há uma tendência a um aumento próximo ao previsto pelo modelo de tendência em séries temporais, a partir do ano de 2008. O crescimento do número de apreensões entre o período de 2005 e 2010 foi de 52,6\%.

Observou-se também um aumento nos resíduos (linha pontilhada), o que sugere que há outros fatores que interferem no aumento da tendência de uso ou porte de maconha.

Figura 8 - Previsão da tendência das apreensões de mulheres com o porte de maconha para o ano de 2012 para a região Norte (M-Norte). Utilizou-se o teste estatístico Exponential Smoothing para a análise de tendência em séries temporais.

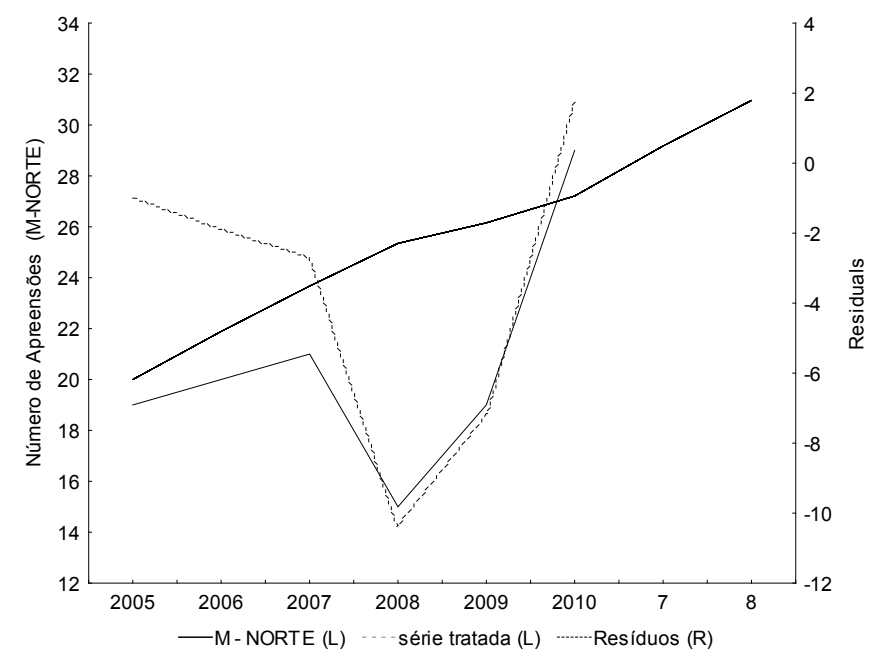

Na figura 9 observa-se que há uma tendência teórica prevista para um aumento ao longo dos anos (linha tracejada) das apreensões de cocaína simultaneamente com maconha. Os dados reais observados (linha contínua) demonstram que há uma tendência a um aumento próximo ao previsto pelo modelo de tendência a partir de 2009. Observou-se um aumento significativo de casos de apreensão entre 2005 e 2010, representado por $437,5 \%$.

A reta dos resíduos (linha pontilhada) representa tudo que está relacionado ao fenômeno estudado e que não foi ou não pode ser mensurado, como a escolha pessoal de participar do tráfico. Apesar de poder acompanhar a reta dos dados reais observados, não há necessariamente que segui-la.

Figura 9 - Previsão da tendência das apreensões de mulheres com o porte de cocaína simultaneamente com maconha para o ano de 2012 para a região Norte (CM-Norte). Utilizou-se o teste estatístico Exponential Smoothing para a análise de tendência em séries temporais.

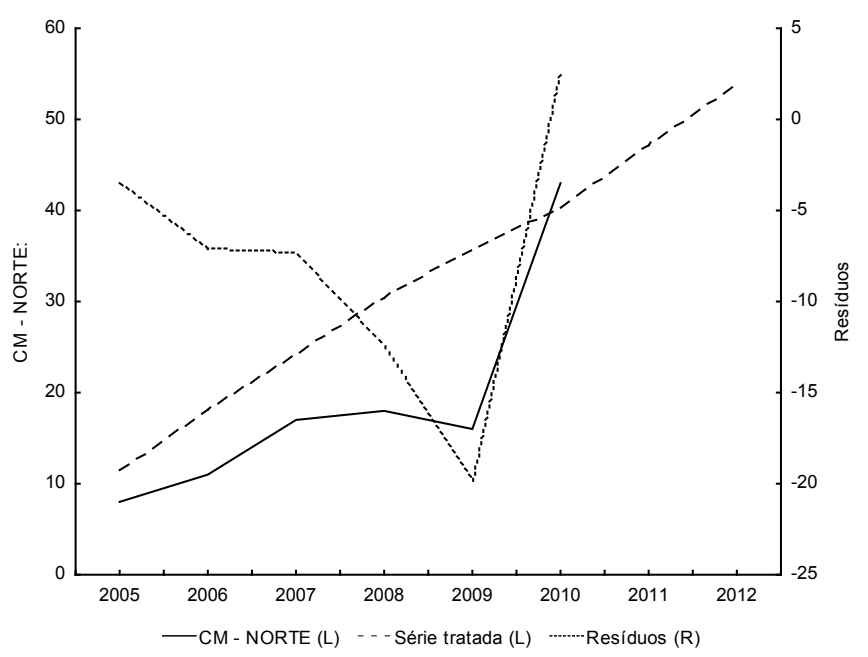

\section{Região da Grande Florianópolis}

Na figura 10 observa-se que há uma tendência teórica prevista para um aumento ao longo dos anos (linha tracejada) das apreensões de cocaína para a região da Grande Florianópolis. Os dados reais observados (linha contínua) demonstram um aumento pontual expressivo em 2008, representando $97,5 \%$ de crescimento em relação a 2005, mostrando em seguida uma tendência a um grande decréscimo até 2010 , representado por $43 \%$ de queda no número de apreensões, mas mostrando-se acima do patamar 
de 2005. Os resíduos (linha pontilhada) expressam a existência de muitas outras variáveis não mensuradas no delineamento, que afetam o ajuste da série observada em relação à série tratada.

Figura 10 - Previsão da tendência das apreensões de mulheres com o porte de cocaína para o ano de 2012 na região da Grande Florianópolis (GRANDE F-C). Utilizou-se o teste estatístico Exponential Smoothing para a análise de tendência em séries temporais.

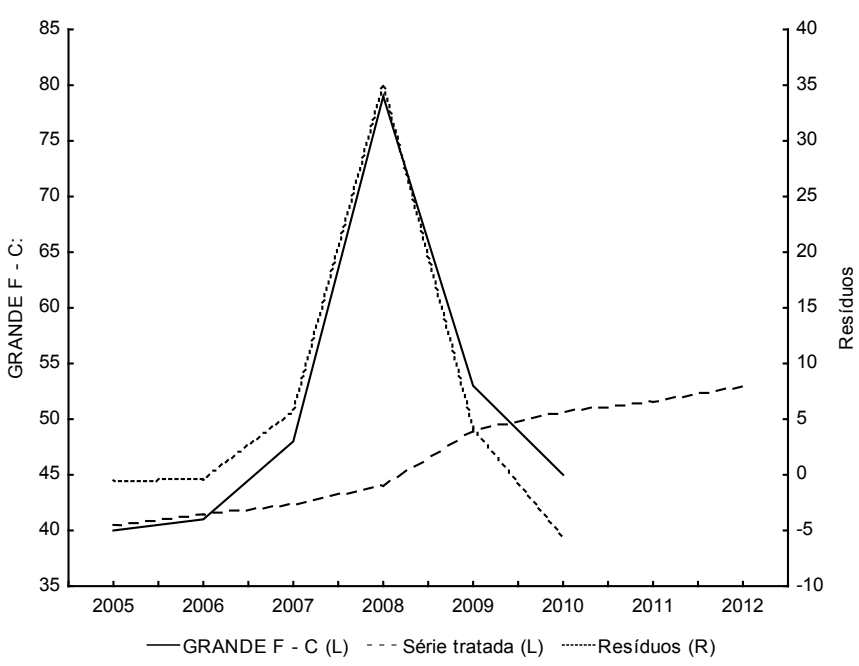

Na figura 11 observa-se que há uma tendência teórica prevista para a estabilidade ao longo dos anos (linha tracejada) das apreensões de maconha para a região da Grande Florianópolis. Os dados reais observados (linha contínua) de 2005 demonstram um número expressivo de apreensões de mulheres com porte de maconha, que foi reduzido de forma significativa até 2009, representando um decréscimo de $25 \%$. A partir de 2009, observou-se uma tendência a um grande aumento, correspondente a um acréscimo de $40 \%$ no número de apreensões. Esse aumento apresenta também um grande crescimento no cálculo para resíduos (linha pontilhada), o que indica que há vários fatores externos que "inflam" os resultados observados.
Figura 11 - Previsão da tendência das apreensões de mulheres com o porte de maconha para o ano de 2012 na região da Grande Florianópolis (GRANDE F-M). Utilizou-se o teste estatístico Exponential Smoothing para a análise de tendência em séries temporais.

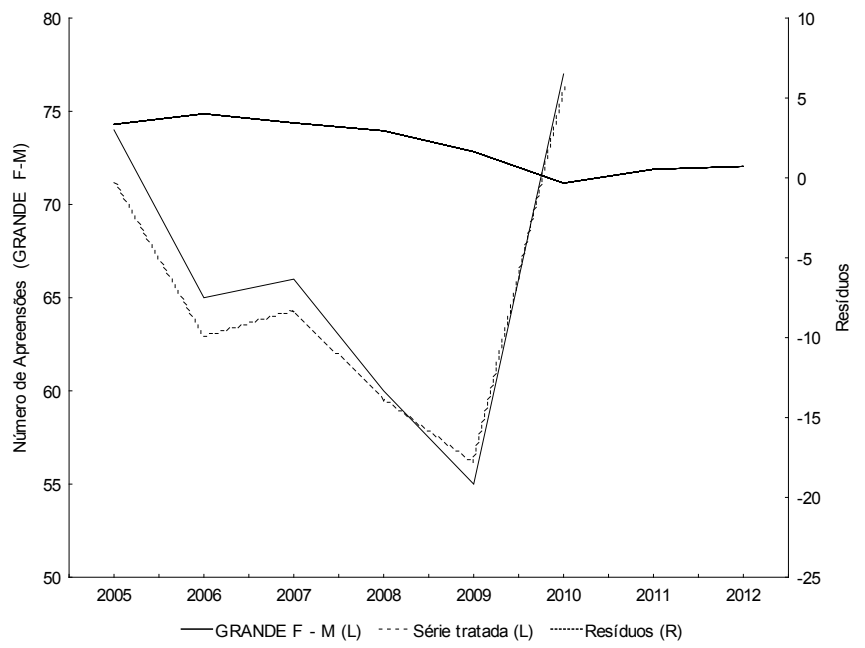

Na figura 12 observa-se que há uma tendência teórica prevista para um aumento ao longo dos anos (linha tracejada) das apreensões de cocaína simultaneamente com maconha para a região da Grande Florianópolis. Os dados reais observados (linha contínua) demonstram oscilação a partir de 2005, com um indicativo de aumento a partir do ano de 2009. Os resíduos (linha pontilhada) expressam a existência de muitas outras variáveis não mensuradas no delineamento, que afetam o ajuste da série observada em relação à série tratada.

Figura 12 - Previsão da tendência das apreensões de mulheres com o porte de cocaína simultaneamente com maconha para o ano de 2012 na região da Grande Florianópolis (GRANDE F-CM). Utilizou-se o teste estatístico Exponential Smoothing para a análise de tendência em séries temporais.

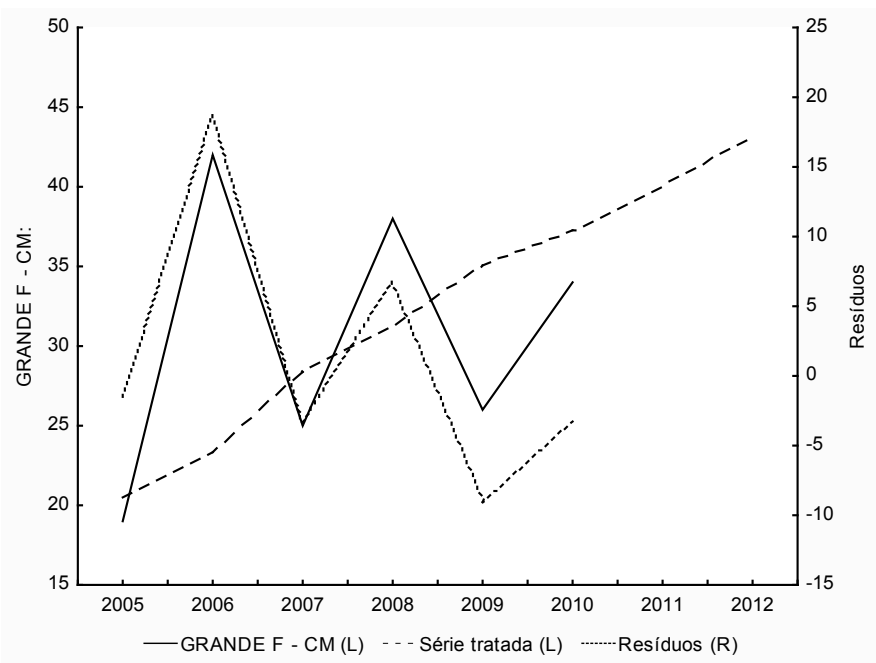




\section{Região Sul}

Na figura 13 observa-se que há uma tendência teórica prevista para um aumento ao longo dos anos (linha tracejada) das apreensões de cocaína para a região Sul. Os dados reais observados (linha contínua) demonstram oscilação a partir de 2005, com um indicativo de grande aumento a partir de 2009, representando uma evolução de $97,5 \%$ entre 2005 e 2010. Os resíduos (linha pontilhada), representação da distribuição potencial dos efeitos das variáveis não medidas em relação ao poder de explicação das variáveis mensuradas, apresentam oscilação, com grande aumento a partir de 2009.

Figura 13 - Previsão da tendência das apreensões de mulheres com o porte de cocaína para o ano de 2012 na região Sul (SUL-C). Utilizou-se o teste estatístico Exponential Smoothing para a análise de tendência em séries temporais.

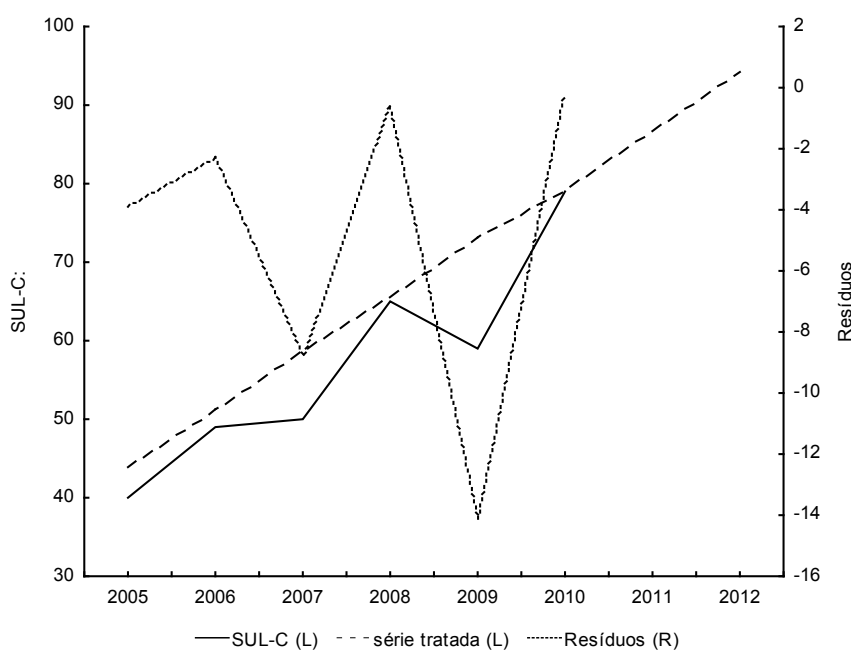

Na figura 14 observa-se uma tendência teórica prevista para um aumento ao longo dos anos (linha tracejada) das apreensões de maconha para a região Sul. Os dados reais observados (linha contínua) demonstram oscilação a partir de 2005, com um indicativo de grande aumento a partir de 2008, que corresponde a um crescimento de $33,3 \%$. Os resíduos (linha pontilhada), variáveis não mensuradas que afetam o ajuste do delineamento da série observada em relação à série tratada, apresentam oscilação, com grande aumento a partir de 2008.
Figura 14 - Previsão da tendência das apreensões de mulheres com o porte de maconha para o ano de 2012 na região Sul (SUL-M). Utilizou-se o teste estatístico Exponential Smoothing para a análise de tendência em séries temporais.

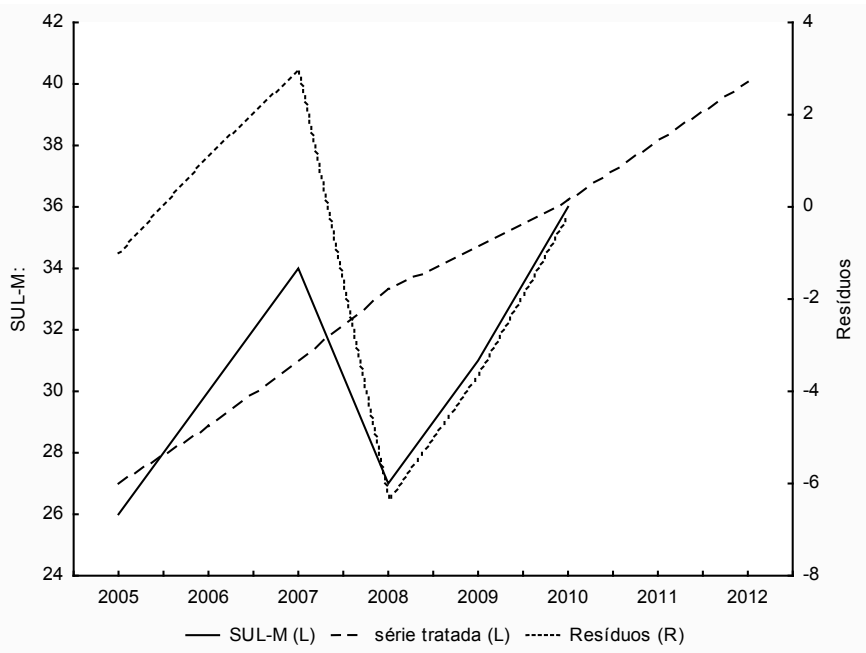

Na figura 15 observa-se que há uma tendência teórica prevista para um aumento ao longo dos anos (linha tracejada) das apreensões de cocaína simultaneamente com maconha para a região Sul. Os dados reais observados (linha contínua) demonstram oscilação amortizada a partir de 2005, com um indicativo de ajuste a partir do ano de 2009, representando um aumento do número de apreensões de $342,8 \%$ entre 2005 e 2010 . Os resíduos (linha pontilhada) apresentam oscilação, com grande aumento a partir de 2009.

Figura 15 - Previsão da tendência das apreensões de mulheres com o porte de cocaína simultaneamente com maconha para o ano de 2012 na região Sul (SUL-CM). Utilizou-se o teste estatístico Exponential Smoothing para a análise de tendência em séries temporais.

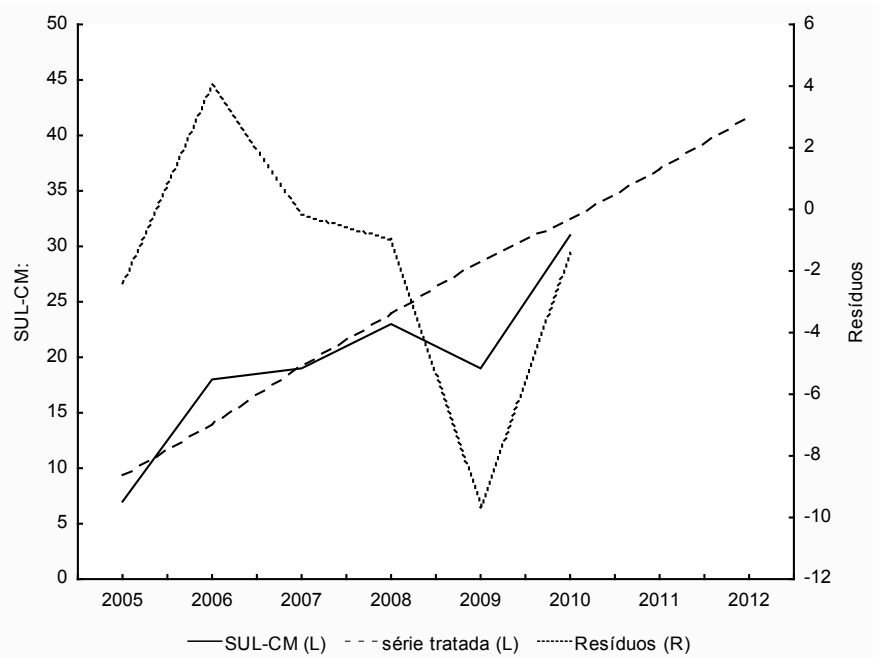




\section{Região do Vale do Itajaí}

Na figura 16 observa-se que há uma tendência teórica prevista para um aumento ao longo dos anos (linha tracejada) das apreensões de cocaína para a região do Vale do Itajaí. Os dados reais observados (linha contínua) demonstram leve oscilação com a linha tratada a partir de 2005, com um indicativo de ajuste a partir do ano de 2009. Esses dados demonstram um crescimento significativo e constante do número de apreensões de mulheres portando cocaína entre 2005 e 2010 , correspondendo a $307,7 \%$ de aumento, o que caracteriza o predomínio de cocaína na região. Os resíduos (linha pontilhada) apresentam oscilação, com grande acréscimo a partir de 2009. Apesar de poder-se acompanhar a reta dos dados reais observados, não há necessariamente que segui-la.

Figura 16 - Previsão da tendência das apreensões de mulheres com o porte de cocaína para o ano de 2012 na região do Vale do Itajaí (V. ITAJAÍ-C). Utilizou-se o teste estatístico Exponential Smoothing para a análise de tendência em séries temporais.

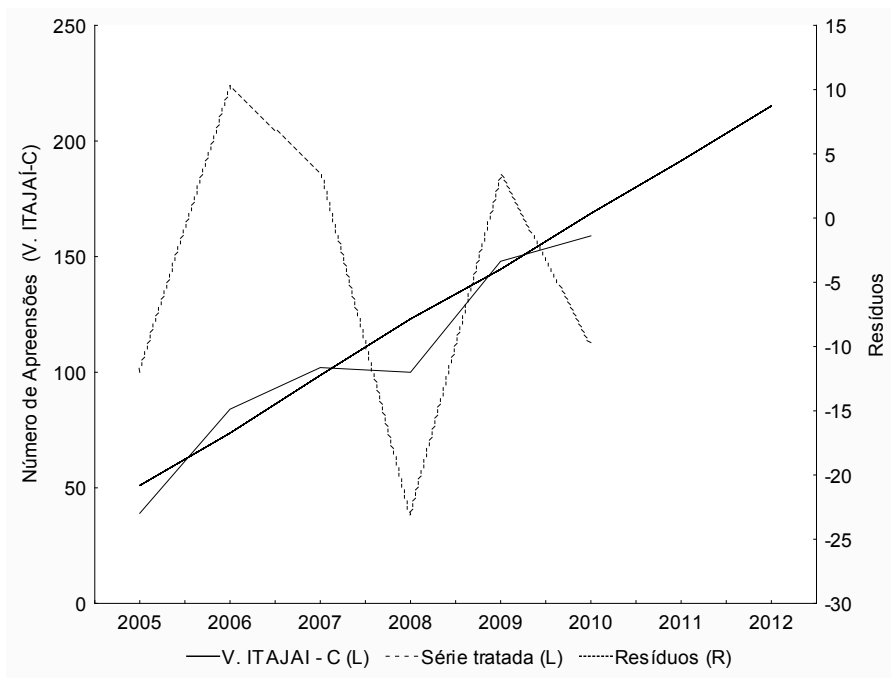

Na figura 17 observa-se uma tendência teórica prevista para um aumento ao longo dos anos (linha tracejada) das apreensões de maconha para a região do Vale do Itajaí. Os dados reais observados (linha contínua) demonstram aumento gradativo a partir de 2006, com um indicativo de ultrapassar o previsto pelo modelo a partir do ano de 2010. O aumento da apreensão de mulheres com o porte de maconha entre 2005 e 2010 representa uma evolução de 40,5\%.
Os resíduos (linha pontilhada), variáveis não mensuradas e relacionadas ao fenômeno estudado, como o aumento de policiamento na região, podem acompanhar ou não a reta dos dados reais observados. A reta dos resíduos demonstra oscilação, com grande aumento a partir de 2009.

Figura 17 - Previsão da tendência das apreensões de mulheres com o porte de maconha para o ano de 2012 na região do Vale do Itajaí (V. ITAJAÍ-M). Utilizou-se o teste estatístico Exponential Smoothing para a análise de tendência em séries temporais.

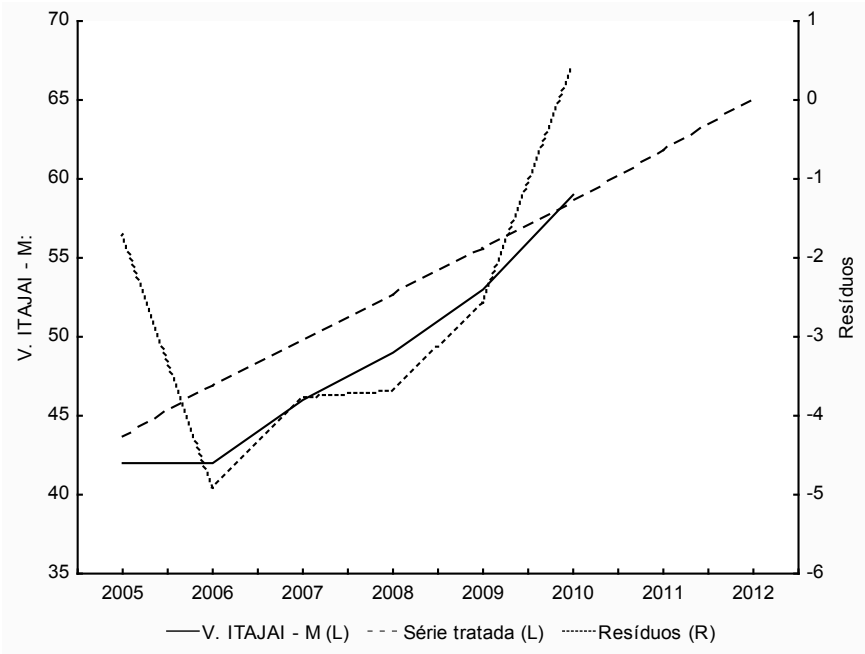

Na figura 18 observa-se que há uma tendência teórica prevista para um aumento ao longo dos anos (linha tracejada) das apreensões de cocaína simultaneamente com maconha para a região do Vale do Itajaí. Os dados reais observados (linha contínua) demonstram aumento gradativo a partir de 2005, com um indicativo de ultrapassar o previsto pelo modelo a partir de 2007 e com tendência de decréscimo a partir de 2009 , representado por $17,8 \%$. O aumento expressivo do número de apreensões entre 2005 e 2009 representa $330,7 \%$.

Os resíduos (linha pontilhada) apresentam leve oscilação, com grande decréscimo a partir de 2009. Apesar de poder acompanhar a reta dos dados reais observados, os resíduos não têm necessariamente que segui-la. 
Figura 18 - Previsão da tendência das apreensões de mulheres com o porte de cocaína simultaneamente com maconha para o ano de 2012 na região do Vale do Itajaí (V. ITAJAÍ-CM). Utilizou-se o teste estatístico Exponential Smoothing para a análise de tendência em séries temporais.

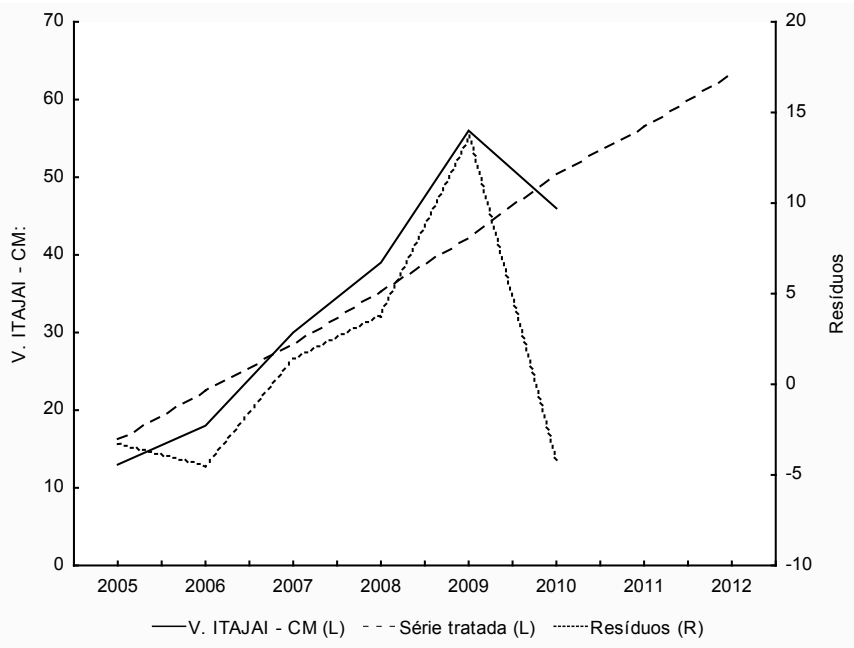

\section{Região do Planalto Serrano}

Na figura 19 observa-se uma tendência teórica prevista para um aumento ao longo dos anos (linha tracejada) das apreensões de cocaína na região do Planalto Serrano. Os dados reais observados (linha contínua) demonstram um grande aumento a partir de 2005, seguido por oscilação do número de apreensões, sendo que a partir de 2009 apresentam tendência à estabilidade.

Os resíduos (linha pontilhada) expressam a existência de muitas outras variáveis não mensuradas no delineamento, que afetam o ajuste da série observada em relação à série tratada.
Figura 19 - Previsão da tendência das apreensões de mulheres com o porte de cocaína para o ano de 2012 na região do Planalto Serrano (PLAN. $\mathrm{S}-\mathrm{C})$. Utilizou-se o teste estatístico Exponential Smoothing para a análise de tendência em séries temporais.

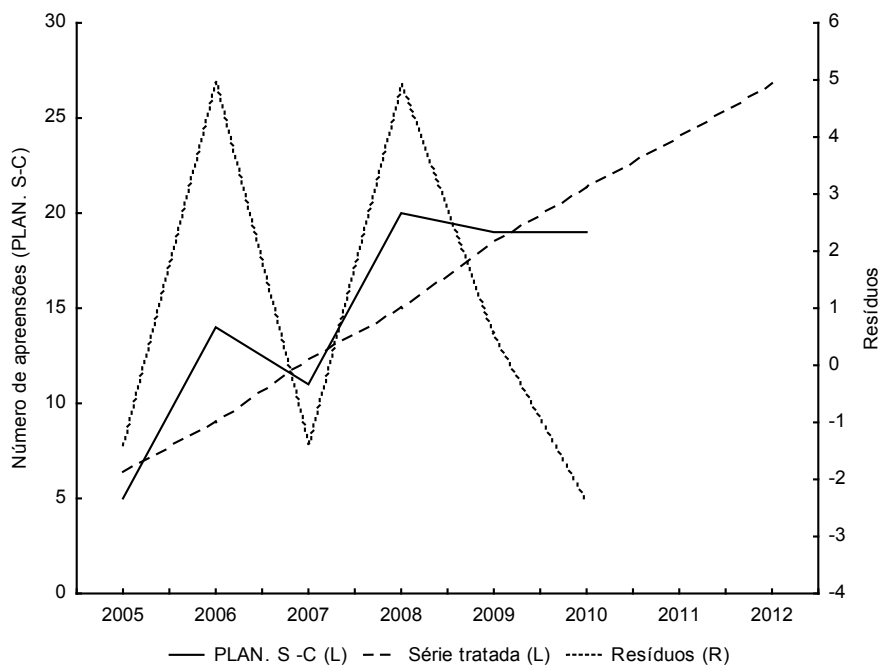

Na figura 20 observa-se uma tendência teórica prevista para um leve aumento ao longo dos anos (linha tracejada) das apreensões de maconha para a região do Planalto Serrano. Os dados reais observados (linha contínua) demonstram um grande aumento no período de 2005 a 2008, representado por $150 \%$ de crescimento do número de apreensões, seguido de um grande decréscimo a partir de 2008, correspondente a $150 \%$ e com tendência de aumento a partir de 2009. Embora exista uma tendência de aumento, observa-se que este fica bem abaixo dos valores esperados pelo modelo de tendência em séries temporais (linha tracejada). Os resíduos (linha pontilhada) expressam a existência de muitas outras variáveis não mensuradas no delineamento, que afetam o ajuste da série observada em relação à série tratada. 
Figura 20 - Previsão da tendência das apreensões de mulheres com o porte de maconha para o ano de 2012 na região do Planalto Serrano (PLAN. S.M). Utilizou-se o teste estatístico Exponential Smoothing para a análise de tendência em séries temporais.

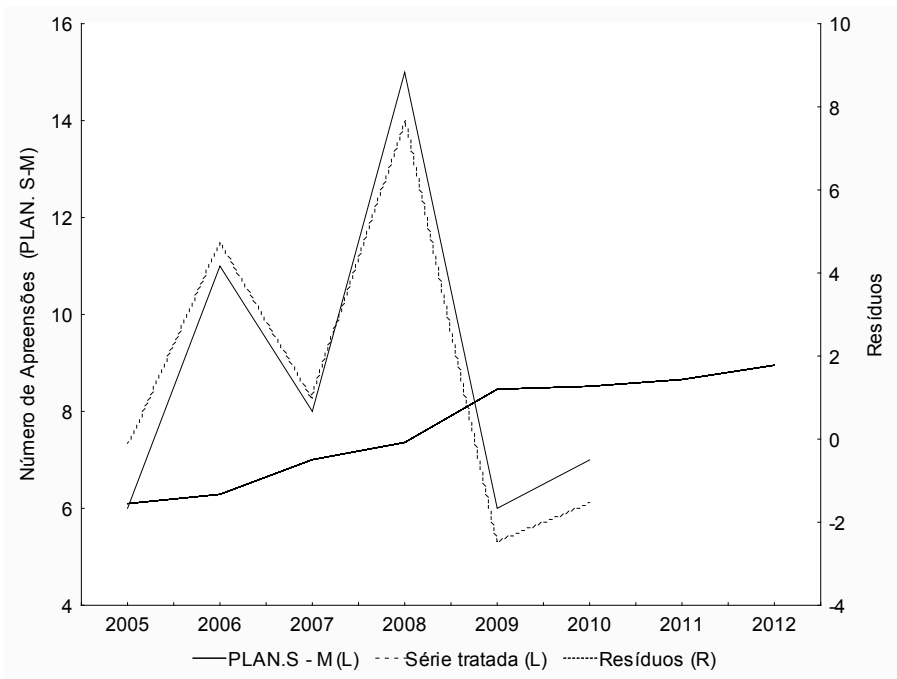

Na figura 21 observa-se que há uma tendência teórica prevista para um aumento ao longo dos anos (linha tracejada) das apreensões de cocaína simultaneamente com maconha para a região do Planalto Serrano. Os dados reais observados (linha contínua) demonstram um grande aumento do número de apreensões entre 2006 e 2008, representado por $200 \%$, um grande decréscimo entre 2008 e 2009 , correspondente a $50 \%$, e uma tendência à estabilização a partir de 2009. Os valores estabilizados estão bem abaixo dos valores previstos pelo modelo de tendência (linha tracejada). Os resíduos (linha pontilhada) expressam a existência de muitas outras variáveis não mensuradas no delineamento, que afetam o ajuste da série observada em relação à série tratada.
Figura 21 - Previsão da tendência das apreensões de mulheres com o porte de cocaína simultaneamente com maconha para o ano de 2012 na região do Planalto Serrano (PLAN. S.-CM). Utilizou-se o teste estatístico Exponential Smoothing para a análise de tendência em séries temporais.

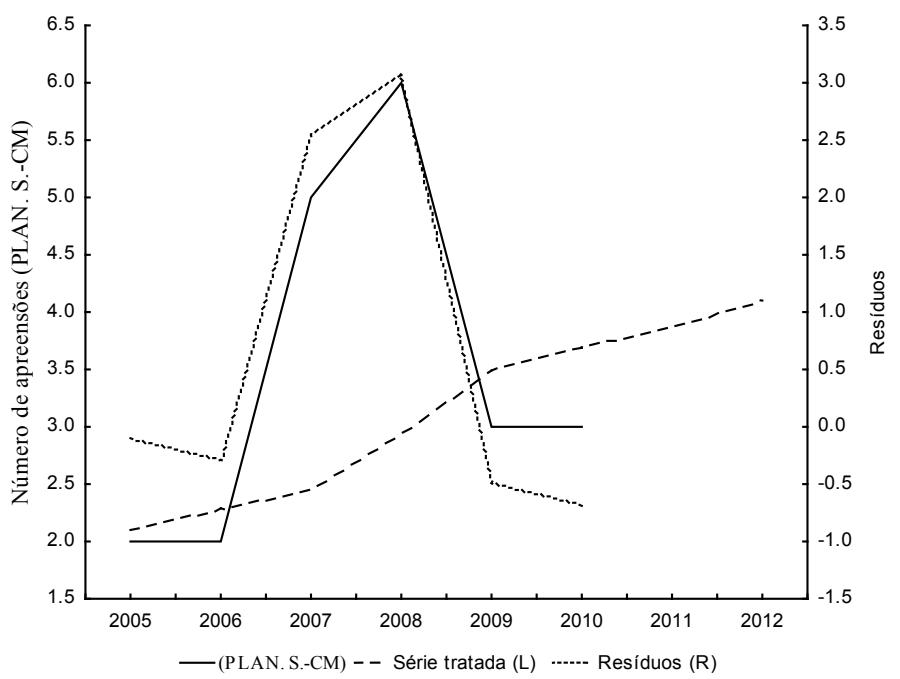

\section{Discussão}

Os resultados deste estudo demonstraram que houve uma evolução do envolvimento de mulheres com o porte de cocaína e maconha no período de 2005 a 2010 em SC, o que configura o aumento do uso e/ou o tráfico desses entorpecentes no decorrer dos anos. Dos 293 municípios de SC, as apreensões ocorreram em 128 cidades, representando 43,7\% dos municípios de todo o Estado. Foram constatadas, no total, 3.645 apreensões de cocaína e maconha, sendo 411 no ano de 2005 e 809 no ano de 2010, demonstrando de forma inequívoca o crescimento, no período, de $96 \%$ de mulheres envolvidas com esses entorpecentes, conforme mostram as figuras 2 e 3 .

$\mathrm{O}$ uso e o abuso de entorpecentes costumam estar presentes em muitas situações de violência. Mais precisamente na região sul do Brasil, os Dados Consolidados do Sistema Penitenciário (Depen, 2005, 2009) mostram uma escalada crescente na criminalidade envolvendo mulheres, no período de 2005 a 2009. Constatou-se que a participação das mulheres foi pequena em relação aos números correspondentes às prisões masculinas; mas, por outro lado, a comparação do número de mulheres prisioneiras em 2009, por diferentes motivos ilícitos, com o número apresentado em 2005, mostra um 
crescimento extremamente significativo: $422,8 \%$ no Paraná $(2005=568,2009=2.970), 58,8 \%$ em Santa Catarina $(2005=636,2009=1.010)$ e $84,1 \%$ no Rio Grande do Sul $(2005=944,2009=1.733)$.

Neste estudo, as apreensões de mulheres envolvidas com o porte de cocaína mostram-se predominantes em cinco das seis regiões de SC, com aumento acentuado na região do Vale do Itajaí. Esse crescimento vertiginoso de cocaína na região correspondeu a uma evolução de $307 \%$ entre 2005 e 2010, conforme mostram as figuras 1 e 16 (linha contínua). Entretanto, nesse mesmo período, os resultados provenientes da somatória das apreensões de todas as regiões mostrou que as ocorrências de cocaína no estado de SC teve um crescimento de $146,6 \%$, com uma tendência de avanço maior para 2011, conforme mostra a figura 2.

As cidades com maior número de apreensões de cocaína na região do Vale do Itajaí foram Camboriú, com 62 casos (61.369 habitantes); Navegantes, com 66 casos (60.038 habitantes); Blumenau, com 93 (299.159 habitantes); Balneário Camboriú, com 116 (106.220 habitantes) e Itajaí, com 135 casos (182.484 habitantes), representando, juntos, 74,7\% do número total de apreensões nessa região (IBGE, 2010). Surpreendentemente, municípios do Vale do Itajaí com populações semelhantes mostraram números bem diferentes nas apreensões de mulheres com porte de cocaína, como Rio do Sul, com 61.058 habitantes ( 16 casos) e Navegantes, com 60.038 habitantes (66 casos); Brusque, com 103.944 habitantes (24 casos) e Balneário Camboriú, com 106.220 habitantes (116 casos) (tabelas dos municípios não incluídas).

Percebe-se que há características importantes em cada município - com relação ao tipo de colonização, educação pública de qualidade e oportunidades de trabalho - que contribuem para o desenvolvimento da cidade e direcionam o jovem para a busca de um futuro sólido. Entretanto, a atividade econômica de uma cidade voltada ao turismo tem a tendência de atrair o comércio ilegal de drogas. Por exemplo, Balneário Camboriú é uma cidade turística que atrai pessoas de várias partes do país, principalmente no verão, e é justamente nessa época do ano que há maior número de apreensões de substâncias psicotrópicas ilegais, tanto com os usuários turistas quanto com os traficantes, que chegam a Balneário Camboriú com a finalidade de obter lucro ilícito com a comercialização de diferentes tipos de drogas de abuso. Por outro lado, Brusque é uma cidade com muitas oportunidades de trabalho. A indústria é a base da economia local, especialmente o setor têxtil e metal-mecânico, mas também o comércio de vestuário, cama, mesa e banho se destacam na geração de renda da cidade. Balneário Camboriú e Brusque são cidades próximas, com populações semelhantes, mas divergem de forma significativa no número de apreensões de cocaína.

Notícia veiculada na imprensa de SC cita que o desemprego é zero nas cidades de Brusque e Jaraguá do Sul (A Notícia, 2012). É perceptível que as oportunidades de empregos aos jovens proporcionam alternativas de mudanças de hábito nessa fase de transição, conduzindo-os a pensar numa carreira profissional e num futuro promissor. Jaraguá do Sul é uma cidade da região Norte com população de 143.123 habitantes e um dos principais parques fabris de SC, grande produtor de malhas, sede de importantes indústrias metal-mecânicas, alimentícias e de uma das únicas fábricas de parapente das Américas (IBGE, 2010).

Apesar de o tráfico de drogas estar em pauta de discussão em muitos governos municipais, sabe-se que as metas a serem atingidas a longo prazo devem ter ação preventiva consistente e combativa nos focos de comércio ilícito, como becos, escolas, bares e boates. Isso requer um sistema organizacional muito bem estruturado, disponibilizado apenas para esse fim, o que é um grande desafio para a maioria das cidades. Não é de agora que escutamos que "é preciso uma revolução nacional, um programa único que unam todos contra o tráfico de entorpecentes, desde a passagem pelas fronteiras do Brasil até o consumidor final".

Um fator importante que explica, pelo menos em parte, o crescimento de apreensões de cocaína na região do Vale do Itajaí é o fato de Itajaí e Navegantes serem cidades portuárias e que não ficam restritas à função comercial, pois, ao atrair capital estrangeiro, movimentam a indústria e o setor de serviços da região. No entanto, esse aparente desenvolvimento é permeado por sérios problemas sociais, que envolvem desde a prostituição até a circulação de bens e drogas ilícitas. Nesses "corredores" ligados ao tráfico e/ou uso de drogas assume importância 
o crescimento de pessoas infectadas por HIV que se prostituíram sem proteção com o companheiro também dependente, ou com o comércio sexual para obter a substância psicotrópica.

Vale a pena ressaltar que Joinville (região Norte) e Florianópolis (região da Grande Florianópolis) são as duas cidades com maior população de SC, correspondendo a 509.293 habitantes e 404.224 habitantes, respectivamente (IBGE, 2010). A somatória das apreensões de mulheres com cocaína e maconha entre 2005 e 2010 em Joinville correspondeu a 280 casos, e em Florianópolis, a 534 casos, demonstrando uma superioridade extremamente importante de apreensões, representando um montante a maior de $46,4 \%$ e $48,3 \%$, respectivamente, em relação à soma dos resultados dos três maiores municípios de suas regiões com relação às apreensões. Norte: Jaraguá do Sul, 60 casos (142.209 habitantes), São Francisco do Sul, 71 casos (41.501 habitantes), e Porto União, 19 casos (33.493 habitantes); Grande Florianópolis: Biguaçu, 55 casos (57.139 habitantes), São José, 108 casos (203.384 habitantes) e Palhoça, 121 casos (135.720 habitantes). Outro ponto importante foi o predomínio de apreensões de cocaína em Joinville; em Florianópolis houve um envolvimento maior de mulheres com o porte de maconha.

Curiosamente, apenas na região da Grande Florianópolis houve um predomínio do porte de maconha em 2010, envolvendo mulheres. Esse perfil foi idêntico ao de 2005, mas distinto de 2008, quando as apreensões de cocaína predominaram, conforme mostram as figuras 10 e 11 (linhas contínuas). Numa visão geral, incluindo todos os resultados obtidos entre 2005 e 2010, a região da Grande Florianópolis mostrou predomínio de apreensões de maconha. Esses resultados estão de acordo com outro trabalho, desenvolvido no Instituto de Análises Forenses de SC, que mostrou que na região metropolitana de Florianópolis, incluindo os municípios de São José, Biguaçu, Palhoça e Florianópolis, as apreensões de maconha, envolvendo homens e mulheres de todas as idades, entre 2005 e 2010, tiveram predomínio, em relação à cocaína na forma básica (crack) e ao cloridrato de cocaína (Oliveira, 2011). Isso indica que esse comércio ilegal tem suas características próprias em determinadas regiões geográficas, onde o consumidor-cliente demonstra preferência para um tipo de entorpecente. $\mathrm{Na}$ avaliação total das seis regiões, o crescimento expressivo de apreensões de maconha em 2010 mostra que este tipo de droga apreendida está avançando no nível estadual, conforme mostra a figura 2 .

A questão do crescimento significativo e constante de apreensões de mulheres com cocaína e maconha, simultaneamente, demonstra maior preocupação com a facilidade de comercialização e consequentemente maior lucro aos traficantes, já que há mais de uma alternativa do produto para diferentes tipos de clientes, ou, ainda, um maior estímulo ao consumo inicial ao jovem que deseja experimentar pela primeira vez uma substância psicotrópica ilegal. O crescimento foi mais expressivo na região da Grande Florianópolis e no Vale do Itajaí (figura 1). Por outro lado, as regiões do Planalto Serrano e Oeste, onde a agricultura e a pecuária são atividades predominantes, apresentaram reduzido número de ocorrências de apreensões de cocaína simultaneamente com maconha, envolvendo mulheres, ratificando que cada região tem as suas características. Se forem voltadas a educação de qualidade, segurança efetiva e oportunidades de emprego, certamente influenciarão na sustentação de um ambiente que não comporta esse comércio ilícito.

A linha da tendência futura de apreensões de cocaína e/ou maconha para 2012, com base nos resultados entre os anos 2005 e 2010, representa o que se espera que tenha ocorrido, caso nada haja mudado em relação àquele ponto. É uma série tratada e transformada, menos suscetível a ruídos ou variações aleatórias (efeitos do acaso), representando uma previsão futura com base em uma suavização estatística dos dados brutos. Devido aos efeitos casuais é necessário utilizar técnicas estatísticas que servem para mostrar um quadro científico mais próximo do que seria o padrão real subjacente ao fenômeno. Os resíduos assinalam que existem muitas outras variáveis, não mensuradas no delineamento, que afetam o ajuste da série observada (dados reais ou brutos) em relação à série tratada (linha de tendência), como um maior ou menor número de intervenções policiais visando apreensões, que inibem ou facilitam, respectivamente, o comércio ilegal de entorpecentes; preocupação com a educação de qualidade; estímulo às informações preventivas ao uso e abuso de drogas em geral, as quais podem atuar como diferencial na região; o envolvimento menor 
ou maior das mulheres com esses tipos de substâncias psicotrópicas ilícitas etc.

Com essas informações, a interpretação se torna mais clara, pois mesmo que exista uma diminuição pontual entre os anos, mas um aumento do número de apreensões em 2010 em relação a 2005, a projeção para o futuro será de aumento, após o tratamento dos dados reais, que suavizam os saltos bruscos. A tendência de decréscimo segue esse mesmo raciocínio, com o inverso dessa situação.

Os resultados mostraram que há uma linha de tendência ao longo dos anos em que houve aumento de apreensões de cocaína e/ou maconha com mulheres nas regiões Norte, Sul, Vale do Itajaí e Planalto Serrano (figuras 7, 8, 9, 13 a 21).

Uma queda pontual foi observada no Vale do Itajaí para as apreensões de cocaína simultaneamente com maconha a partir de 2009, mas bem acima do patamar observado em 2005 (figura 18). Dessa forma, estatisticamente ocorre uma tendência de apresentação de acréscimo, considerando que outros fatores não mensurados tenham influenciado esse decréscimo dos dados reais observados em 2010. Da mesma forma, isso ocorreu com as apreensões de cocaína simultaneamente com maconha no Planalto Serrano (figura 21). Entre 2009 e 2010 os dados reais mostram uma situação de estabilidade para as apreensões desses dois entorpecentes, mas a previsão futura é de um acréscimo, devido aos dados reais observados de 2005 mostrarem-se menores. A interpretação é que ocorreu algo que diminuiu o valor real em relação ao valor esperado. A situação pontual de diminuição do número de apreensões em 2010 também foi observada com as apreensões de cocaína na região Oeste e Grande Florianópolis (figuras 1 e 10, linha contínua), mas com tendência de previsão futura para um aumento de apreensões desse entorpecente. Por outro lado, a tendência das apreensões de maconha ao longo dos anos na região Oeste mostra uma diminuição, em contraposição a um aumento dos dados reais a partir do ano de 2009, mantendo-se o mesmo raciocínio do inverso dessa situação.

Na região da Grande Florianópolis há dois picos expressivos de apreensões de maconha (figura 11, linha contínua), envolvendo mulheres, em 2005 e em 2010, com tendência de previsão futura de estabilidade desse comércio ilícito. A partir de 2009 já pode ser observado que houve uma tendência de aumento dos dados reais, acompanhado de um grande aumento no cálculo para resíduos, o que indica que há vários fatores externos, não mensurados, que inflam os resultados reais coletados.

Com os resultados obtidos, pode-se inferir que houve tendência de aumento do número de apreensões de mulheres portando cocaína e maconha no decorrer dos anos, mostrando de forma clara que é preciso investir numa estrutura estadual forte e persistente, voltada à prevenção, à repressão nos focos de tráfico e ao tratamento das usuárias dependentes, protegendo a sociedade e principalmente as jovens, que são mais vulneráveis.

As pessoas buscam em grandes centros oportunidades de trabalho e nem sempre têm êxito. Mulheres pobres, de baixa escolaridade e sem qualificação profissional, com filhos para criar e precisando trabalhar, ainda não usufruem das conquistas feministas das últimas décadas. Por outro lado, há a problemática da família e drogas, em que a esposa de traficante ou de usuário de drogas chega a exaustão emocional, ficando vulnerável ao surgimento de distúrbios emocionais e consequente desestruturação familiar, que possibilita o seu envolvimento com substâncias ilícitas, quer pelo seu efeito farmacológico, quer pela oportunidade de um rendimento para sua subsistência.

O art. 6o da Constituição Brasileira (Redação EC 64/2010) cita que são direitos sociais a educação, a saúde, a alimentação, o trabalho, a moradia, o lazer, a segurança, a previdência social, a proteção à maternidade e à infância e a assistência aos desamparados. Mas a realidade para muitas pessoas é outra. Com relação à moradia, parte da população mais carente busca com suas próprias forças um espaço para viver em aglomerados nas favelas, restabelecendo um pouco da autoestima e da dignidade, dando à família um teto, por mais simples que seja. A falta de alternativas de moradia implica que as crianças cresçam no meio do crime e das gangues de traficantes, que encontram nas favelas um lugar propício para se esconder, administrar e dominar o seu comércio ilegal de drogas. Ali as crianças têm o primeiro contato com essas substâncias, e, quando um pouco maiores, são requisitadas para o trabalho de "levar e trazer" e com isso passam a ter uma pequena remuneração que as estimulam a permanecer 
no "trabalho". Quando adolescentes, alguns dizem que desejam ser "bandidos" - que para eles representa um conceito de coragem, poder e riqueza, valorizado dentro das gangues infiltradas nas favelas.

Por outro lado as meninas se tornam mais vulneráveis pela exploração sexual. Quando adolescentes, são presas fáceis desse grupo insensível e inconsequente. Ainda com sonhos de menina, que busca viver num ambiente de carinho e respeito, elas se veem presas a uma vida solitária, muitas vezes já numa situação prematura de mãe e sem condições de procurar um caminho fora do tráfico de drogas. Assim sendo, é comum a participação de adolescentes do sexo feminino em atos ilegais e isso muitas vezes é proporcionado por relacionamentos com namorados e companheiros, integrantes do tráfico, que as envolvem em atividades de "bastidores". O que marca essas relações familiares é a sequência de abandonos vivenciada por essas meninas, o que gera, entre outras consequências, a dificuldade em projetar limites, por ausência de regras claras, fixas e constantes (Corrêa, 2011).

Quando em situação de dependência química, não é raro a mulher sofrer violência doméstica e abuso sexual. O uso de drogas está intimamente relacionado à violência, seja como fator desencadeante, seja como efeito. Sabe-se que a mulher dependente química tem um risco maior de ser vítima de agressão, pois em geral é pouca a sua capacidade de operar a própria proteção (Bessa et al., 2010). Nesse ambiente hostil, com o organismo dependente de uma substância psicotrópica, infinitamente minúscula, a mulher usa o próprio corpo para a obtenção da droga, ficando refém desse ambiente por muito tempo. Não é raro meninas dependentes de crack desaparecerem de suas casas e só voltarem depois de uma ou duas semanas, após os neurotransmissores se depletarem e seu organismo não mais reagir ao uso do crack. Essa rotina, vivenciada pelas famílias de dependentes, conduz a problemas sociais imensos que devem ser abordados com toda a seriedade, enfatizando a preocupação de implantar projetos educativos já na pré-adolescência, bem como tratamentos dignos e gratuitos para a mulher, que atualmente não existem nem em SC, nem em muitos outros estados brasileiros.

Os resultados deste estudo, expressivos e esclarecedores, servem de alerta e alicerce para o de- senvolvimento de políticas estaduais fortes, visando enfatizar os problemas relacionados com cocaína, maconha e mulher, na tentativa de alterar o quadro atual. Sabe-se que o uso desses entorpecentes traz grandes problemas à sociedade e à usuária, culminando em um grande impacto negativo nas oportunidades de trabalho futuro e de renda, bem como em problemas sociais sérios nas gerações que convivem no ambiente ilícito.

Com base neste trabalho é possível sugerir a replicação deste estudo em outros estados brasileiros, para traçar um panorama da situação real do envolvimento de mulheres com entorpecentes no Brasil.

\section{Referências bibliográficas}

BESSA, Marco Antonio; BARROS, Marina Carvalho de Moraes; MITSUHIRO, Sandro Sendin; GUINSBURG, Ruth; CHALEM, Elisa; LARANJEIRA, Ronaldo. (2010), "Correlates of substance use during adolescent pregnancy in São Paulo, Brazil". Revista Brasileira de Psiquiatria, 32, 1: p. 66-69.

CARLINI, Elisaldo Araújo; GALDURÓZ, José Carlos Fernandes; NOTO, Ana Regina; CARLINI, Cláudia Masur; OLIVEIRA, Lúcio Garcia; NAPPO, Solange Aparecida; MOURA, Yone Gonçalves; SANCHEZ, Zila van der Meer. (2006), "II Levantamento Domiciliar sobre Uso de Drogas Psicotrópicas no Brasil: estudo envolvendo as 108 maiores cidades do país-2005". São Paulo: Centro Brasileiro de Informação sobre Drogas Psicotrópicas (Cebrid), Universidade Federal de São Paulo.

CAZENAVE, Sílvia de Oliveira Santos (1999). Prevalência do uso de drogas na região de Campinas. Tese de doutorado. São Paulo: Faculdade de Ciências Farmacêuticas da Universidade de São Paulo.

CHODOROW, Nancy (1978). "The relation to the mother and the mothering relation", in N. Chodorow (org.). The reproduction of mothering (with a New Preface). Berkeley and Los Angeles, California: University of California Press.

Departamento Penitenciário Nacional (Depen). Sistema Penitenciário no Brasil - dados consolidados. Brasília: Ministério da Justiça, 2005, 2009.

Escritório das Nações Unidas sobre Drogas e Crime (Unodc) (2010). "Relatório Mundial sobre Drogas WDR 2010, Referências ao Brasil e ao Cone Sul". Disponível em:

<http://www.unodc.org/documents/southerncone//Topics drugs/WDR/2010/WDR_2010_Referencias_ao_Brasil_e_ Cone_Sul.pdf $>$. Acesso em: $10 \overline{\text { jul.2011. }}$ 
Instituto Brasileiro de Geografia e Estatística (IBGE) (Censo 2010). "Dados Santa Catarina". Disponível em:

$<$ http://www.censo2010.ibge.gov.br/dados_divulgados/ index.php?uf=42>. Acesso em: 4 set.2012.

National Institute on Drug Abuse (NIDA) (2010), "Research Report Series, Cocaine: Abuse and Addiction". Disponível em: $\quad<$ http://www.nida.nih.gov/PDF/RRCocaine.pdf $>$. Acesso em: 10 jul.2011.

OLIVEIRA, Maria Lita Francisco (2011). Evolução das apreensões de drogas na região metropolitana de Florianópolis. Monografia de especialização. Florianópolis: Assessoria Universitária Pedagógica de Extensão (Aupex).

CORRÊA, Claudia Abreu Amorim (2011). Mulheres de dependentes químicos: noções do impacto da dependência química sobre suas vidas. Monografia de especialização. São Paulo: Universidade Federal de São Paulo (Unifesp).

QUEIROZ, Vinícius Eduardo (2008). A questão das drogas ilícitas no Brasil. Monografia de bacharelado em ciências econômicas. Florianópolis: Faculdade de Ciências Econômicas da Universidade Federal de Santa Catarina.

Artigo Submetido: 11/06/2013

Artigo Aprovado: 13/09/2013 